\title{
Meningkatkan Pembelajaran dan Kompetensi Siswa SMK Bina Insan Mandiri Melalui Pelatihan Software Akuntansi Myob Di Wilayah Srengseng Jakarta Barat
}

\author{
Putri Dwi Wahyuni ${ }^{1}$, Mariyam Chairunisa ${ }^{2}$, Fairas Panca Yudha ${ }^{3}$ \\ 1,2,3 Universitas Mercu Buana \\ Jakarta, Indonesia \\ e-mail: ${ }^{1}$ putri.dwi@mercubuana.ac.id, ${ }^{2}$ mariyam.chairunisa@mercubuana.ac.id, \\ ${ }^{3}$ fairas.py@gmail.com
}

\begin{abstract}
Abstrak
Perkembangan era revolusi industri 4.0 saat ini memberikan dampak yang signifikan terhadap proses pelaporan keuangan yang sebelumnya manual menjadi berbasis sistem Untuk menghadapi perkembangan teknologi di bidang akuntansi, maka setiap institusi pendidikan harus mempersiapkan lulusannya untuk bisa menghadapi tantangan tersebut. Lulusannya diharapkan dapat mempunyai softskill di bidang akuntansi yaitu dengan menguasi salah satu software akuntansi diantaranya MYOB Accounting. Pelatihan software akuntansi MYOB dapat memberikan manfaat bagi siswa SMK Bina Insani Mandiri dalam meningkatkan pembelajaran dan kompetensi dalam menyusun laporan keuangan baik perusahaan jasa, dagang maupun manufaktur. Pelatihan ini memiliki tujuan agar siswa SMK Bina Insani Mandiri dapat memahami dan menggunakan software akuntansi MYOB dengan baik. Setelah kegiatan ini siswa diharapkan dapat meningkatkan pembelajaran dan kompetensi dibidang akuntansi dalam menyusun laporan keuangan secara cepat dan tepat dengan menggunakan software akuntansi MYOB. Metode pelaksanaan dengan praktik menggunnakan MYOB V13 melalui zoom. Hasil kegiatan yang telah dilaksanakan menyatakan bahwa para peserta puas atas materi yang disampaikan dan studi kasus yang dipraktikkan langsung melalui zoom meeting. Para peserta juga antusias pada setiap materi yang disampaikan. Hal ini dibuktikan dengan banyaknya peserta yang bertanya kepada narasumber.
\end{abstract}

Kata Kunci: Pelatihan, Software MYOB, SMK Bina Insan Mandiri

\begin{abstract}
MYOB accounting software training can provide benefits for students of SMK Bina Insani Mandiri in improving learning and competence in preparing financial reports for service, trading and manufacturing companies. This training has the aim that students of SMK Bina Insani Mandiri can understand and use MYOB accounting software well. After this activity, students are expected to be able to improve learning and competence in the field of accounting in preparing financial reports quickly and accurately using MYOB accounting software. The results of the activities that have been carried out stated that the participants were satisfied with the material presented and the case studies were put into practice directly
\end{abstract}


through the zoom meeting. The participants were also enthusiastic about every material presented. This is evidenced by the number of participants who asked the speakers.

\section{Keywords: Trainin, g MYOB Software, SMK Bina Insan Mandiri}

\section{Pendahuluan}

Perkembangan era revolusi industri 4.0 saat ini memberikan dampak yang signifikan terhadap proses pelaporan keuangan yang sebelumnya manual menjadi berbasis sistem dengan tujuan agar penyusunan laporan keuangan disajikan secara cepat, tepat dan akurat sehingga pengambilan keputusan menjadi tidak bias. Pada lingkungan kerja saat ini, tugas dan pekerjaan harus dapat dikerjakan dengan cepat sehingga telah diambil alih oleh mesin otomatis. Untuk dapat bersaing dengan tenaga kerja lainnya baik secara nasional maupun internasional diperlukan Sumber Daya Manusia (SDM) yang terampil, ahli dan kreatif (Cahyadi, 2019). Untuk menghadapi perkembangan teknologi di bidang akuntansi, maka setiap institusi pendidikan harus mempersiapkan lulusannya untuk bisa menghadapi tantangan tersebut. Lulusannya diharapkan dapat mempunyai softskill di bidang akuntansi yaitu dengan menguasi salah satu software akuntansi diantaranya MYOB Accounting.

Praktek penggunaan software akuntansi MYOB dimasukkan dalam kurikulum pendidikan jurusan akuntansi mulai dari Sekolah Menengah Kejuruan (SMK) sampai dengan perguruan tinggi. SMK merupakan suatu bentuk satuan pendidikan formal yang menyelenggarakan pendidikan kejuruan. Lulusan SMK diharapkan dapat langsung terjun ke dunia kerja dengan dibekali keahlian tertentu sesuai dengan jurusannya. Salah satunya keahlian yang diharapkan dari lulusan SMK yaitu ahli dalam pengoperasian aplikasi akuntansi secara komputerisasi.

Penguasaan siswa dalam mata pelajaran ini ditujukan supaya siswa dapat mengkombinasikan perkembangan teknologi dengan bidang ilmu akuntansi guna memecahkan berbagai siklus akuntansi pada berbagai jenis bidang usaha yang ada baik untuk perusahaan jasa, dagang maupun untuk perusahaan manufaktur. MYOB Accounting memiliki banyak keunggulan jika dibandingkan dengan aplikasi jenis software akuntansi yang lain yaitu lebih mudah digunakan (userfriendly) dengan tampilan menu dan aliran transaksi yang sederhana dan mudah diingat (Siregar, 2019). MYOB Accounting merupakan suatu software aplikasi akuntansi keuangan yang memudahkan pencatatan transaksi keuangan suatu organisasi. Aplikasi ini dapat menyajikan informasi keuangan tepat waktu dan mudah digunakan MYOB Accounting merupakan suatu software akuntansi yang digunakan untuk membuat laporan keuangan. Pengguna hanya memasukan transaksi ke dalam modul yang tersedia dalam program tersebut untuk menghasilkan laporan keuangan (Zulfiar, Busra, Faisal, \& Mawaddah, 2018). Program MYOB sangat bermanfaat bagi para siswa baik tingkat SMK maupun SMA pada dunia kerja sebagai tenaga administrasi di perusahaan.(Lubis 2007: 3 dalam (Sakti \& Anwar, 2020).

Dari hasil wawancara yang dilakukan kepada pihak sekolah Bina Insan Mandiri, hasil pembelajaran software akuntansi MYOB masih kurang efektif ditambah kondisi pandemi COVID-19 saat ini sehingga kegiatan yang dibutuhkan oleh para siswa kelas II dan III SMK Bina Insan Mandiri Jurusan Akuntansi mendalami pembuatan laporan keuangan menggunakan software akuntansi MYOB dan digunakan untuk ujian kompetensi di kelas III. Hal ini dilakukan guna menyelaraskan kebutuhan sekolah dengan kegiatan pengabdian kepada masyarakat Universitas Mercu Buana, sehingga kerja sama yang akan dilakukan dapat memberikan manfaat. Tujuan dan manfaat dari pelatihan yang dilakukan yaitu untuk 
meningkatkan kompetensi siswa dan siswi SMK Bina insan Mandiri, pelatihan berkaitan dengan penyusunan laporan keuangan menggunakan software akuntansi MYOB, Kegiatan pengabdian kepada masyarakat ini diharapkan berkelanjutan sehingga dapat terus mendukung dan membina siswa dan siswi SMK Bina Insan Mandiri

\section{Metode}

1. Rencana Kegiatan

Program pelatihan dirancang untuk memberikan bekal pemahaman siswa atas penguasaan MYOB Accounting secara terintegrasi mulai dari pengenalan sofwarenya hingga praktik pembuatan laporan keuangan. Dengan mempertimbangkan alokasi waktu dan sumber daya yang relevan, kegiatan pelatihan dikemas secara efektif dan efisien dengan menggunakan pendekatan simulasi dan studi kasus.

2. Khalayak Sasaran

Program Pengabdian Masyarakat berbasis Ipteks bagi Masyarakat (IbM) ini khalayak sasarannya adalah para siswa SMK Bina Insan Mandiri Jurusan Akuntansi di wilayah Srengseng Jakarta Barat.

3. Metode Kegiatan

Metode yang digunakan dalam kegiatan ini adalah dalam bentuk pelatihan penggunaan software akuntansi MYOB, dengan memberikan materi penggunaan aplikasi software akuntansi MYOB. Materi sosialisasi dapat berupa :

1) Pengetahuan tentang memulai dasar akuntansi.

2) Pengetahuan mengenai Software akuntansi MYOB

3) Pengetahuan mengenai cara menggunakan software akuntansi MYOB mulai dari set up hingga input transaksi

4) Pengetahuan menyajikan laporan keuangan perusahaan

Setelah pengabdian ini berjalan diharapkan siswa mampu memulai mengaplikasikan software akuntansi MYOB untuk menambah keahlian yang dimiliki secara bertahap sehingga semakin banyak siswa yang memiliki kompetensi yang diinginkan banyak perusahaan.

\section{Hasil dan Pembahasan}

\section{Hasil}

Meningkatkan Pembelajaran Dan Kompetensi Siswa SMK Bina Insani Mandiri Melalui Pelatihan Software Akuntansi MYOB di Wilayah Srengseng Jakarta Barat. Kegiatan ini diadakan dengan rincian sebagai berikut:
Hari
: Rabu
Tanggal
: 27 Januari 2021
Waktu
: $09.00 \mathrm{~s} / \mathrm{d} 14.00$
Lokasi
:Webinar via zoom
Meeting ID : 9112721822
Jumlah Peserta : 101 orang

https://zoom.us/j/9112721822?pwd=MFk1MUtiT2JKbVI0RTBSQlpTZ2hOUT09

Kegiatan ini terdiri dari dua sesi, yaitu: 


\section{ABDITEKNIKA}

Jurnal Pengabdian Kepada Masyarakat

1) Sesi pertama yaitu pemberian materi mengenai software MYOB

Pelatihan ini memaparkan mengenai definisi MYOB, kelemahan dan kelebihan MYOB, pengenalan software MYOB mulai dari menu-menunya dan cara setting awal database didalamnya.

2) Sesi kedua yaitu tanya jawab peserta mengenai software MYOB

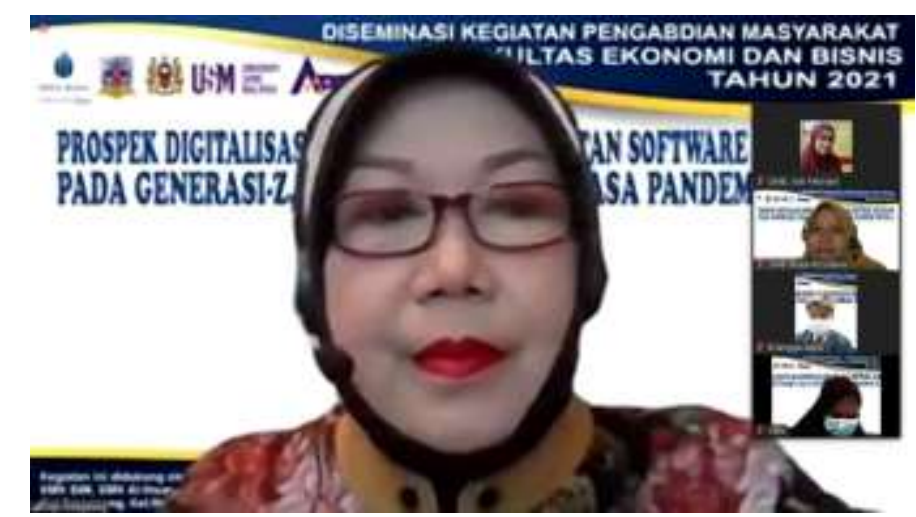

Gambar 1. Sambutan Dr. Inge Hutagalung Selaku Kepala PPM

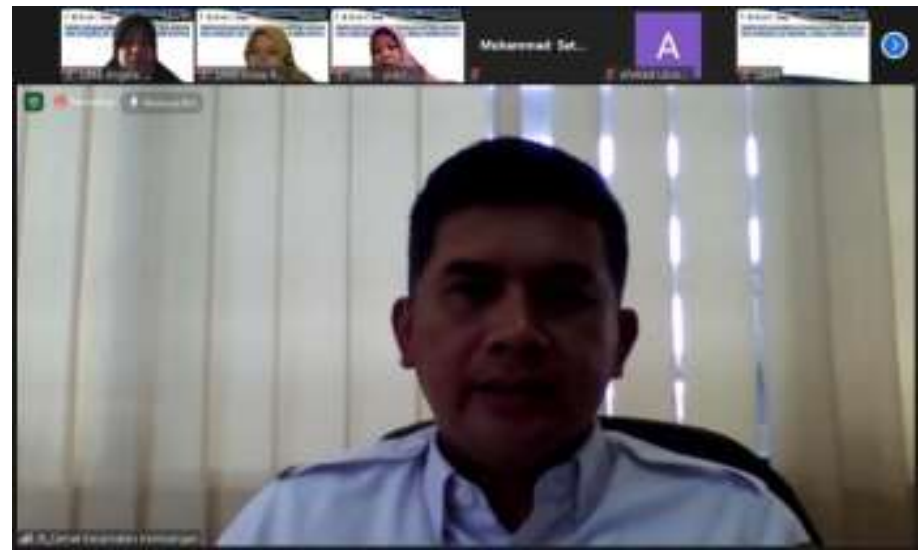

Gambar 2. Sambutan Kepala Kecamatan Kembangan Drs. Joko Mulyono

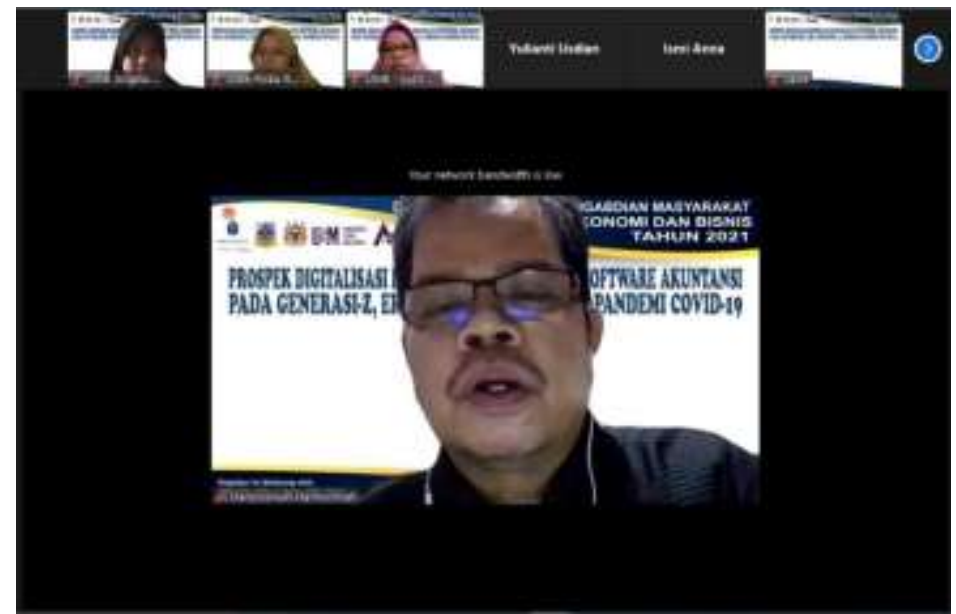

Gambar 3. Sambutan Dekan Fakultas Ekonomi dan Bisnis, Dr. Harnovinsah 


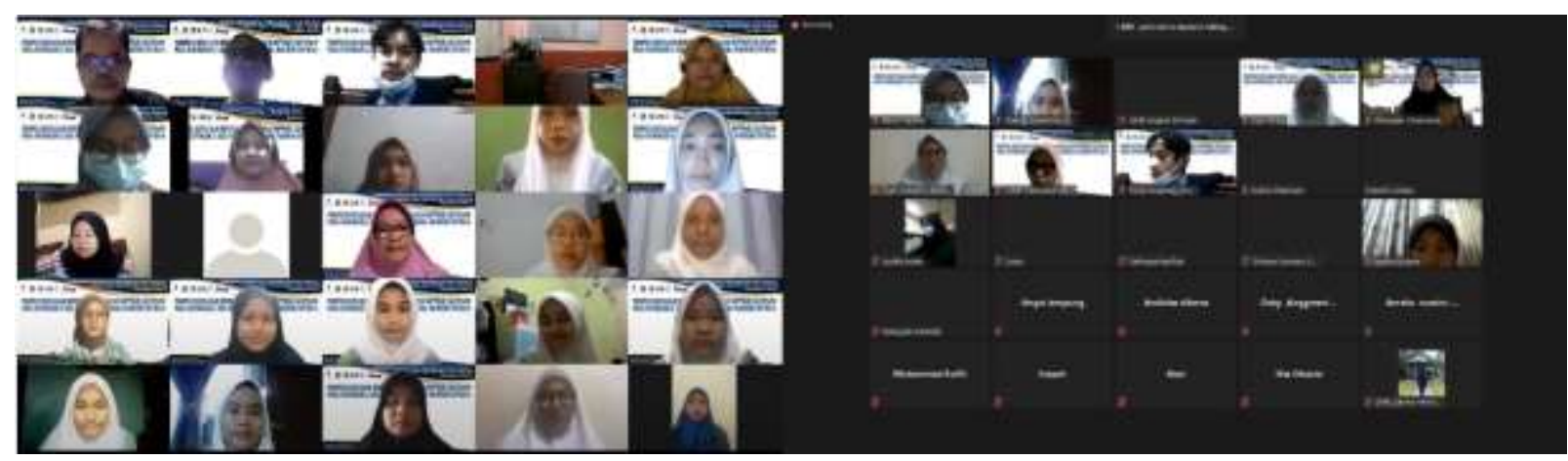

Gambar 4. Foto Bersama Dengan Peserta

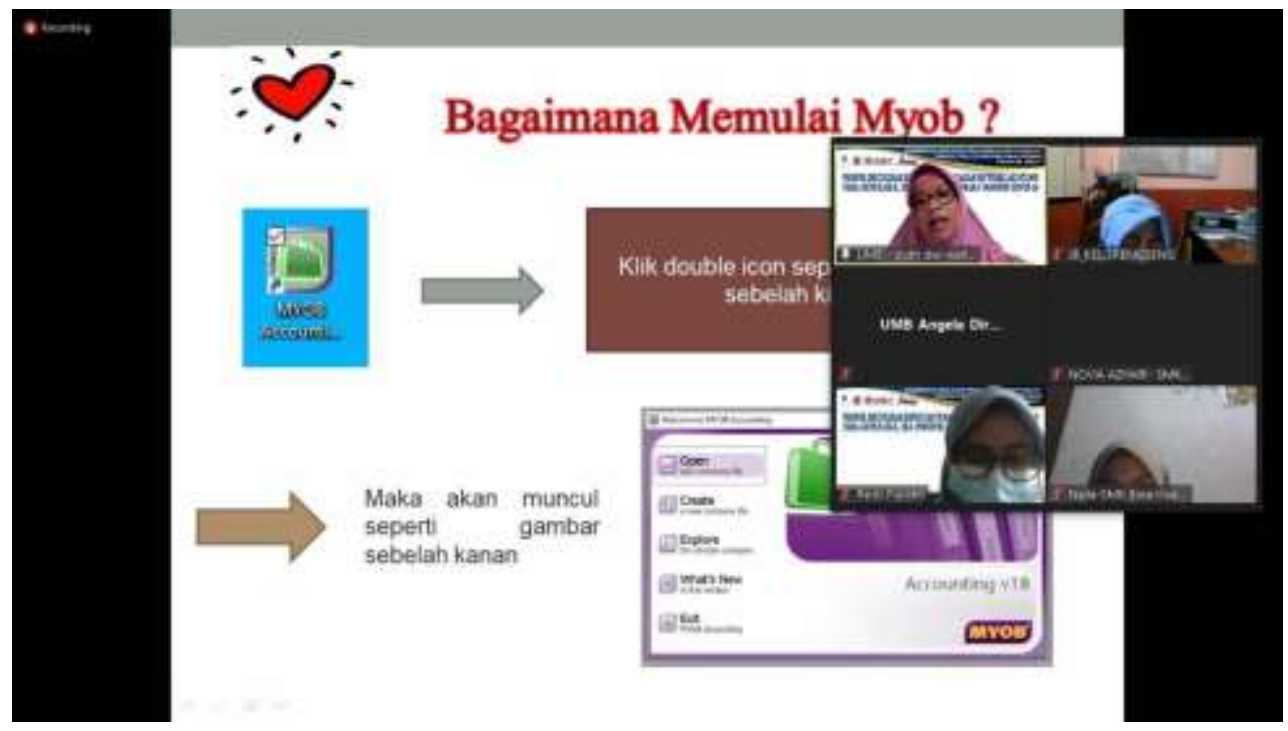

Gambar 5. Pemaparan Narasumber (Putri Dwi Wahyuni, SE.,M.Ak)

Mengenai Pengenalan MYOB

\section{Pembahasan}

Pemanfaatan software akuntansi (MYOB) pada khalayak sasaran dapat digunakan untuk mempermudah dalam penyusunan laporan keuangan agar hasilnya akurat dan efisiensi waktu pengerjaan sehingga informasi yang disampaikan cepat diperoleh bagi user. Selain itu, bagi siswa-siswi SMK dapat beguna pada uji kompetensi sebagai persyaratan kelulusan yang ditentukan oleh sekolah.

Evaluasi kegiatan pengabdian masyarakat ini dilakukan melalui pengisian kuesioner oleh para peserta. Evaluasi kegiatan terkait dengan manfaat dan kepuasan para peserta terhadap kegiatan pengadian kepada masyarakat yang dilaksanakan. Pengelompokan penilaian responden dikategorikan kedalam tiga kelompok, yaitu tinggi, sedang dan rendah (Ferdinand, 2014) yang dapat dilihat pada tabel 1 dibawah ini. 
Tabel 1. Pedoman Kategorisasi Rata-rata Skor Penilaian Responden

\begin{tabular}{cc}
\hline Rata-Rata Skor & Kriteria \\
\hline $1,00-2,00$ & Rendah \\
$2,01-3,00$ & Sedang \\
$3,01-4,00$ & Tinggi \\
\hline
\end{tabular}

Berdasarkan Tabel 1, pengelompokan penilaian para peserta dikategorikan ke dalam tiga kelompok. Pengelompokan penilaian dimaksudkan untuk mengetahui masing-masing kuesioner tersebut dengan melihat rata-ratanya dinilai oleh para peserta dengan kriteria tinggi, sedang dan rendah. Berikut hasil evaluasi kegiatan oleh para peserta yang dapat dilihat pada Tabel 2

Tabel 2 Hasil Evaluasi Kegiatan Pengabdian Kepada Masyarakat

\begin{tabular}{|c|c|c|c|c|c|c|c|}
\hline No. & Uraian & $\begin{array}{c}\text { Sangat } \\
\text { Setuju (4) }\end{array}$ & $\begin{array}{c}\text { Setuju } \\
\text { (3) }\end{array}$ & $\begin{array}{l}\text { Kurang } \\
\text { Setuju (2) }\end{array}$ & $\begin{array}{c}\text { Tidak } \\
\text { Setuju (1) }\end{array}$ & Mean & Kriteria \\
\hline 1 & $\begin{array}{l}\text { Menyelesaikan masalah yang } \\
\text { dihadapi masyarakat dengan } \\
\text { memanfaatkan keahlian sivitas } \\
\text { akademik yang relevan }\end{array}$ & 33 & 68 & 0 & 0 & 3,33 & Tinggi \\
\hline 2 & Memanfaatkan teknologi tepat guna & 43 & 58 & 0 & 0 & 3,43 & Tinggi \\
\hline 3 & $\begin{array}{l}\text { Berguna bagi pengembangan ilmu } \\
\text { pengetahuan dan teknologi }\end{array}$ & 49 & 52 & 0 & 0 & 3,49 & Tinggi \\
\hline 4 & $\begin{array}{l}\text { Berguna sebagai bahan ajar atau } \\
\text { modul pelatihan untuk pengayaan } \\
\text { sumber belajar }\end{array}$ & 46 & 55 & 0 & 0 & 3,46 & Tinggi \\
\hline 5 & Meningkatkan pendapatan & 22 & 68 & 11 & 0 & 3,11 & Tinggi \\
\hline 6 & Meningkatkan pengetahuan & 57 & 44 & 0 & 0 & 3,56 & Tinggi \\
\hline 7 & Meningkatkan produksi & 34 & 65 & 2 & 0 & 3,32 & Tinggi \\
\hline 8 & $\begin{array}{l}\text { Merubah perilaku kearah yang } \\
\text { positif }\end{array}$ & 52 & 48 & 1 & 0 & 3,50 & Tinggi \\
\hline 9 & Meningkatkan mutu lingkungan & 42 & 58 & 1 & 0 & 3,41 & Tinggi \\
\hline 10 & $\begin{array}{l}\text { Kerjasama yang dilaksanakan } \\
\text { bersama UMB melalui kegiatan } \\
\text { Pengabdian Kepada Masyarakat } \\
\text { bermanfaat bagi masyarakat }\end{array}$ & 53 & 48 & 0 & 0 & 3,52 & Tinggi \\
\hline 11 & $\begin{array}{l}\text { Kerjasama yang dilaksanakan } \\
\text { bersama UMB melalui kegiatan } \\
\text { Pengabdian Kepada Masyarakat } \\
\text { memenuhi } \\
\text { target kerjasama }\end{array}$ & 50 & 50 & 1 & 0 & 3,49 & Tinggi \\
\hline \multicolumn{6}{|c|}{ Rata-Rata } & 3,42 & Tinggi \\
\hline
\end{tabular}

Berdasarkan tabel 1, pengelompokan penilaian para peserta dikategorikan ke dalam tiga kelompok. Pengelompokan penilaian untuk mengetahui nilai dari masing-masing kuesioner dengan melihat nilai rata-rata yang dinilai oleh para peserta dengan kriteria tinggi, sedang dan rendah. 
Berdasarkan Tabel 2 dapat dilihat bahwa rata-rata penilaian peserta terhadap kegiatan pengabdian masyarakat ini adalah tinggi yaitu dengan nilai rata-rata mean sebesar 3,42. Hal ini menunjukkan bahwa para peserta puas dan merasakan adanya manfaat dari kegiatan pengabdian masyarakat ini. Para peserta dapat menerima dan memahami dengan baik setiap sesi yang dilaksanakan dalam kegiatan pengabdian kepada masyarakat ini. Selain itu, peserta pun memberikan saran-saran di dalam kuesioner evaluasi kegiatan. Saran-saran yang diberikan oleh para peserta antara lain kegiatan yang bermanfaat seperti ada lagi kegiatan seperti ini, sangat menambah pengetahuan mengenai MYOB dan menurut peserta sudah cukup jelas karena materi yang diberikan sangat bermanfaat dan berguna apalagi sekarang zaman serba teknologi. Berdasarkan saran yang diberikan peserta dapat disimpulkan bahwa bahwa para peserta merasa puas dan merasakan adanya manfaat dari kegiatan pengabdian kepada masyarakat ini. Selain itu, berikut ini hasil evaluasi kegiatan yang berkaitan dengan tema kegiatan berjudul Meningkatkan Pembelajaran Dan Kompetensi Siswa SMK Bina Insani Mandiri Melalui Pelatihan Software Akuntansi MYOB di Wilayah Srengseng, Jakarta Barat.

Tabel 3

Hasil Evaluasi Kegiatan Pengabdian Kepada Masyarakat Bertema Meningkatkan Pembelajaran Dan Kompetensi Siswa SMK Bina Insani Mandiri Melalui Pelatihan Software Akuntansi MYOB

\begin{tabular}{|c|c|c|c|c|c|c|c|}
\hline No. & Uraian & $\begin{array}{l}\text { Sangat } \\
\text { Setuju } \\
\text { (4) }\end{array}$ & $\begin{array}{l}\text { Setuju } \\
\text { (3) }\end{array}$ & $\begin{array}{l}\text { Kurang } \\
\text { Setuju } \\
\text { (2) }\end{array}$ & $\begin{array}{l}\text { Tidak } \\
\text { Setuju } \\
\text { (1) }\end{array}$ & Mean & Kriteria \\
\hline & Perkembangan & 44 & 56 & 1 & 0 & 3,43 & Tinggi \\
\hline 1 & $\begin{array}{l}\text { komputerisasi akuntansi saat ini } \\
\text { sudah pesat? }\end{array}$ & & & & & & \\
\hline 2 & $\begin{array}{l}\text { Teknologi komputerisasi akuntansi } \\
\text { perlu dikembangkan kembali }\end{array}$ & 48 & 51 & 2 & 0 & 3,46 & Tinggi \\
\hline 3 & $\begin{array}{l}\text { Software akuntansi } \\
\text { (MYOB/Accurate) mudah untuk } \\
\text { dioperasikan }\end{array}$ & 23 & 70 & 8 & 0 & 3,15 & Tinggi \\
\hline 4 & $\begin{array}{l}\text { Fitur yang disediakan software } \\
\text { akuntansi yang telah saudara } \\
\text { gunakan sudah lengkap sesuai } \\
\text { dengan kebutuhan perusahaan di } \\
\text { Indonesia }\end{array}$ & 22 & 76 & 3 & 0 & 3,19 & Tinggi \\
\hline 5 & $\begin{array}{l}\text { Saudara menggunakan sumber- } \\
\text { sumber informasi baik berupa } \\
\text { buku, koleksi audio/visual, dan } \\
\text { lain-lain dalam proses kegiatan } \\
\text { pembelajaran software akuntansi? }\end{array}$ & 22 & 77 & 2 & 0 & 3,20 & Tinggi \\
\hline \multicolumn{6}{|c|}{ Rata-Rata } & 3,28 & Tinggi \\
\hline
\end{tabular}

Berdasarkan Tabel 3 dapat dilihat bahwa rata-rata penilaian peserta terhadap kegiatan pengabdian masyarakat ini adalah berkategori tinggi yaitu dengan nilai rata-rata mean sebesar 3,28. Hal ini menunjukkan bahwa para peserta mudah memahami materi yang disampaikan dan setuju dengan pemanfaatan software akuntansi (MYOB) dapat meningkatkan pembelajaran dan kompetensi di era industri 4.0. Para peserta juga antusias berdiskusi seputar pemanfaatan software akuntansi (MYOB). 


\section{Kesimpulan}

Secara keseluruhan, peserta pelatihan memahami materi yang disampaikan dan bisa memanfaatkan software akuntansi (MYOB) dengan baik dalam penyusunan laporan keuangan Suasana kegiatan sangat kondusif dan peserta aktif berdiskusi Secara keseluruhan peserta menyatakan sangat puas terhadap kegiatan yang diadakan dan berharap diadakan lagi kegiatan serupa dengan tema yang berbeda.

Kegiatan pengabdian ini mendapat respon yang positif dari mitra dan peserta. Kegiatan pengabdian ini dapat ditindaklanjuti pada waktu berikutnya terutama kegiatan-kegiatan yang berkaitan dengan pemberian wawasan dan pengetahuan yang bermanfaat mengenai software akuntansi karena teknologi semakin berkembang maju.

\section{Daftar Pustaka}

Cahyadi, I. F. (2019). Peranan Sistem Informasi Akuntansi dan Tantangan Profesi Akuntan di Era Revolusi Industri 4.0 (Sebuah Studi Fenomenologi). AKTSAR (Jurnal Akuntansi Syariah), 2(1), 69-82.

Ferdinand, A. T. (2014). Metode penelitian manajemen (5th ed.). Semarang: Universitas Diponegoro.

Sakti, H. G., \& Anwar, Z. (2020). Effektivitas Penggunaan Media MYOB Pembelajaran Terhadap Hasil Belajar Siswa Pada Mata Pelajaran Akuntansi Kelas XI di SMKN 1 Sakra Kabupaten Lombok Timur Tahun Ajaran 2019/2020. Jurnal Cahaya Mandalika, 1(2), 1-10.

Siregar, I. F. (2019). Pelatihan Penggunaan Aplikasi Komputer Akuntansi Sebagai Media Untuk Meningkatkan Kompetensi Dan Pembelajaran Bagi Guru Dan Siswa SMK N 1 Tapung. Diklat Review : Jurnal Manajemen Pendidikan Dan Pelatihan, 2(3), 227-232. https://doi.org/10.35446/diklatreview.v2i3.311

Zulfiar, E., Busra, Faisal, \& Mawaddah, N. (2018). Pelatihan Aplikasi MYOB Accounting Bagi Siswa SMK Negeri 5 Kota Lhokseumawe. Proceeding Seminar Nasional Politeknik Negeri Lhokseumawe, 2(1), 1-4.

https://bim.sch.id/profil-sekolah/ 